\title{
O autocultivo de Cannabis e a tecnologia social Cannabis self-cultivation and social technology
}

\author{
Monique Batista de Oliveira ${ }^{a}$ \\ (iD) https://orcid.org/0000-0002-7642-0971 \\ E-mail: moniqueboliveira®gmail.com \\ Miguel Said Vieira ${ }^{b}$ \\ (iD) https://orcid.org/0000-0002-4339-7429 \\ E-mail: miguel.vieira®ufabc.edu.br \\ Marco Akerman ${ }^{\mathrm{a}}$ \\ (D) https://orcid.org/0000-0003-1522-8000 \\ E-mail: marcoakermanळusp.br \\ aniversidade de São Paulo. Faculdade de Saúde Pública. \\ Programa de Pós-Graduação em Saúde Pública. São Paulo, \\ SP, Brasil. \\ bUniversidade Federal do $A B C$. Centro de Engenharias e Ciências \\ Sociais. Santo André, SP, Brasil.
}

\section{Correspondência}

Miguel Said Vieira

Universidade Federal do ABC. Av. dos Estados, 500I. Santo André, SP, Brasil. CEP 09210-580.

\section{Resumo}

O objetivo deste trabalho é analisar o autocultivo de Cannabis para fins medicinais no Brasil, avaliando em que medida a prática poderia ser enquadrada como uma tecnologia social, na formulação de Renato Dagnino. Com base em dados coletados em trabalho de campo (entrevistas semiestruturadas) em dois centros urbanos no Brasil (São Paulo, Rio de Janeiro) e de uma participante nos Estados Unidos, identificam-se características dessas práticas que as aproximam de uma tecnologia social, como a adaptação a pequena escala, o atendimento a demandas sociais por meio de trabalho cognitivo, a participação ativa de produtores e usuários em seu desenvolvimento, e a ausência de diferenciação entre patrão e empregado. Pondera-se, entretanto, que a noção de tecnologia social está bastante ligada a um objetivo de transformação do setor produtivo, o que talvez limite a aplicação desse conceito em situações de produção não-comercial, para atendimento de necessidades diretas; e que a consideração dos riscos na produção de medicamentos talvez torne pouco aconselhável a generalização de práticas caseiras como a do autocultivo. Propõe-se que essa situação poderia ser remediada com o emprego de estratégias de ciência aberta e cidadã, envolvendo o diálogo com instituições públicas do campo tecnológico e científico.

Palavras-chave: Maconha Medicinal; Autocultivo de Cannabis; Tecnologia Social. 


\section{Abstract}

The objective of this study is to analyze Cannabis self-cultivation for medicinal purposes in Brazil, evaluating to what extent the practice may fit into the framework of what Renato Dagnino termed a social technology. Based on data collected during fieldwork (semi-structured interviews) carried out in two Brazilian urban centers (São Paulo and Rio de Janeiro) and from a participant in the United States, we identified characteristics of these practices that make them akin to a social technology: adaptation to small-scale production, use of cognitive labor to meet social demands, active participation of producers and users in the practice's development, and lack of differentiation between boss and employee. It is worth noting, however, that the notion of social technology is closely linked to the objective of transforming the productive sector. This may limit the application of this concept to non-commercial production aimed at satisfying direct needs. Moreover, given the risks involved in the production of medicines, the generalization of homemade practices such as self-cultivation may not be advisable. These issues could be remedied by the use of open, democratic and citizen-oriented scientific strategies, involving dialogue with public institutions in the technological and scientific field.

Keywords: Medical Marijuana; Cannabis Selfcultivation; Social Technology.

\section{Uso da maconha medicinal no Brasil e autocultivo}

Em meados de 2014, o debate sobre a maconha medicinal no Brasil ganhou força com o início de uma intensa controvérsia sobre pedidos na justiça para uso do canabidiol (CBD), um dos compostos da Cannabis (Pais..., 2014). Já foram reconhecidos no CBD diversos potenciais terapêuticos, como o controle de convulsões em epilepsias refratárias e a redução dos sintomas da doença de Parkinson (Brucki et al., 2015).

A pressão social e o aval de parte da comunidade científica nesse processo levaram à reclassificação do CBD pela Agência Nacional de Vigilância Sanitária (ANVISA, 2015a), que passou a ser considerado um composto controlado (lista $\mathrm{C} 1$ ). Com isso, a agência regulamentou e permitiu o uso legal de um composto derivado da Cannabis sativa no Brasil para fins medicinais e tratamento individual, desde que comprovada a necessidade médica com prescrição. ${ }^{1}$

Meses antes, o Conselho Federal de Medicina (CFM, 2014) havia permitido que médicos prescrevessem o CBD para epilepsias sem tratamento disponível. Ambas as decisões versavam apenas sobre o CBD - tido como menos capaz de deflagrar alterações psicoativas -, e não sobre a planta como um todo. No período, o CBD era importado dos Estados Unidos por pacientes, a um custo que podia chegar a R\$ 10 mil por mês (Oliveira, 2016). 0 alto custo da importação, aliado a discussões sobre possíveis efeitos terapêuticos de outros compostos da Cannabis sativa, como o tetrahidrocanabinol (THC), provocaram um debate sobre o uso da maconha in natura e seus efeitos medicinais. Nesse contexto, um grupo de cultivadores passou a produzir óleo extraído da planta e a distribuílo para algumas famílias (Oliveira, 2016); outras ainda brigaram na Justiça para conseguir o direito ao autocultivo para fins medicinais (Justiça..., 2016).

Embora o presente artigo enfoque o período mencionado anteriormente, quando ocorreu o primeiro debate institucional e social mais intenso sobre a Cannabis medicinal no Brasil, cabe lembrar que a controvérsia segue ativa. Em 2019 a Anvisa

\footnotetext{
1 De acordo com a Resolução n ${ }^{0} 17$ (ANVISA, 2015b), o CBD foi incluso na lista C1, que versa sobre medicamentos de controle especial. Antes, o composto não constava em nenhuma lista da Anvisa, mas era considerado proibido por ser entendido como um derivado da Cannabis sativa. A planta permaneceu na lista de plantas proscritas no Brasil (lista E); portanto, com seu uso in natura proibido.
} 
passou a permitir no país o comércio de produtos e medicamentos com compostos da Cannabis, mas rejeita pedido de permissão para o autocultivo da planta (Cannabis..., 2019). Um mês depois, a agência também simplificou o processo de importação (Cruz, 2020).

No que tange aos impactos da regulamentação do CBD na saúde pública, não registramos trabalhos acadêmicos que façam uma avaliação sistemática da influência da permissão para importação no Brasil. Há, contudo, relatos de estudos locais e na imprensa que apontam para uma crescente judicialização do CBD, que passou a ser custeado pelo Sistema Único de Saúde (SUS) após ações judiciais (Gurgel et al., 2019; Oliveira; Ribeiro, 2017). Levantamento da Folha de S.Paulo mostrou que pedidos na Justiça para custeio do composto em São Paulo aumentaram $1.750 \%$ entre 2015 e 2019; e ainda havia pressão para a permissão do autocultivo via judicialização, com 44 pedidos já autorizados em 2019 (Collucci, 2019b). Há também, atualmente, experiências de autocultivo coletivo de maconha para fins medicinais que conseguiram se legalizar via ação judicial. É o caso da Associação Brasileira de Apoio Cannabis Esperança (Abrace), que reúne pacientes em João Pessoa (PB), e que conseguiu via Justiça, em 2017, autorização da Anvisa para o plantio de maconha e produção do óleo medicinal, e hoje atende 2.50o pessoas (Collucci, 2019a).

\section{Tecnologia social}

Um conceito bastante rico para analisar o autocultivo de Cannabis no contexto contemporâneo que envolve simultaneamente a ampliação da aceitação do uso dessa planta (em particular do uso medicinal), e a integração da sua produção e comercialização a circuitos formalizados da economia capitalista - é o de tecnologia social. Nesta seção apresentaremos esse conceito. Embora ele seja utilizado por diversos autores e organizações que discutem desenvolvimento e transformação social, nos baseamos aqui na abordagem de Renato Dagnino (2014). Para compreendê-la, porém, é preciso antes abordar de forma sumária o contexto de debate mais amplo em que ela surge, e duas noções que a influenciam diretamente.

Comecemos pelo contexto. No decorrer do século XX, a problematização das noções de desenvolvimento (e subdesenvolvimento) ganhou corpo. Com contribuições decisivas como as de Frantz Fanon (1968) - na sua pioneira análise da decolonização, do colonialismo e de seus efeitos na subjetividade -, formou-se o campo de estudos do pós-colonialismo; campo que, em trabalhos como os de Arturo Escobar (2008), apontou a importância de reconhecer o sujeito específico promovido pelo neoliberalismo, e de criticá-lo com vistas a pensar a alteridade: os outros modos de vida, sujeitos, paradigmas civilizacionais existentes ou possíveis. A ideia de que o Norte Global deva ser um modelo a ser copiado é posta em questão em ondas de choque que atingiram diversos campos - inclusive na economia e nos estudos de política científica e tecnológica (onde se situa Dagnino).

É no caldo desse contexto que se desenvolvem os dois conceitos que influenciam a abordagem de Dagnino (2014): o de tecnologia apropriada e o de economia solidária.

A noção de tecnologia apropriada ganha notoriedade com o trabalho de Ernst Schumacher, principalmente seu livro Small Is Beautiful (1973), publicado no Brasil como O negócio é ser pequeno. Um dos aspectos centrais de seu trabalho é o questionamento da ideia de que o uso da tecnologia mais avançada seria sempre a melhor opção, independentemente do contexto; ao contrário, ele sustenta que a mera transposição das tecnologias de ponta para o Sul Global ${ }^{2}$ não garante o desenvolvimento socioeconômico, e ainda ameaça a sustentabilidade do planeta. A tecnologia apropriada

\footnotetext{
2 As expressões "Sul Global" e "Norte Global" descrevem diferenças entre regiões e populações no mundo; à diferença de expressões utilizadas anteriormente nas ciências sociais (como "primeiro mundo"/“terceiro mundo”, que enfatizava o impacto da Guerra Fria na geopolítica mundial; ou "desenvolvidos"/“subdesenvolvidos”, que coloca o desenvolvimento como um ideal civilizacional supostamente universal), elas enfatizam as desigualdades de poder, os efeitos continuados do colonialismo, a resistência a eles oferecida, e os atores e conhecimentos tipicamente invisibilizados nessa dinâmica. É importante notar também que, nessas expressões, os países não são sempre tomados como unidades homogêneas: elas incorporam a ideia de interseccionalidade, considerando que fazem parte do Sul Global aquelas populações no interior de países do "Norte" que também sofrem os efeitos das desigualdades de poder e do colonialismo (tais como negros/as, imigrantes etc., a depender da sociedade em questão). Para uma visão introdutória sobre o tema, consultar Dados \& Connell (2012).
} 
busca ser mais adequada ao contexto em que é utilizada; suas principais diferenças em relação à tecnologia convencional são o custo acessível, com menor investimento por posto de trabalho envolvido; a escala pequena de produção, com menor risco de prejudicar o ambiente; e o maior espaço dado à criatividade humana, "humanizando" o trabalho.

A noção de tecnologia apropriada tem diversas ressonâncias com o pensamento crítico sobre ciência e tecnologia produzido na periferia do capitalismo como os trabalhos de Amilcar Herrera (1971), no caso da América Latina. Isso não é mero acaso: a estratégia de desenvolvimento via transposição da tecnologia de ponta convencional, amplamente defendida durante as décadas dos "Trinta Gloriosos" após a Segunda Guerra Mundial, provocou um agravamento das relações de dependência das nações pobres, que passavam a ter que comprar das nações ricas pacotes tecnológicos extremamente caros, sem possuir autonomia para desenvolvê-los ou mesmo adaptá-los, e com os quais prosseguiam em condições bastante desiguais (e subordinadas) de inserção no mercado global. A chamada Revolução Verde, transformação no setor agrícola de regiões do Sul Global ocorrida durante os anos 1950 e 1960, é um bom exemplo dos problemas dessa estratégia: centrada na mecanização e no uso intensivo de agroquímicos, e visando o aumento da produtividade por meio de monocultivos em larga escala, ela terminou por acentuar desigualdades socioeconômicas no interior desses países, incluindo um aumento da concentração da propriedade da terra (Dunn, 1978, p. 67-69), e ampliou a dependência dessas nações em relação ao Norte Global, em função da centralidade que tiveram na Revolução Verde os insumos derivados de petróleo e os equipamentos industriais, patenteados.

Já a economia solidária, por sua vez, é uma proposta para reorganizar paulatinamente o sistema produtivo (com forte influência do movimento cooperativista), visando garantir a igualdade de direitos entre cidadãos. As duas características principais desse novo modo de produção - cujo principal teórico e incentivador político, no Brasil, foi o economista Paul Singer (2002) - são a posse coletiva dos meios de produção e a autogestão; a primeira permitiria uma distribuição menos desigual dos ganhos aferidos com a produção, e a segunda democratizaria o processo produtivo, colocando as decisões fundamentais nas mãos dos trabalhadores (e não nas mãos de investidores, acionistas ou administradores).

A tecnologia social, na formulação de Dagnino (2014), conjuga essas duas noções: de um lado, a valorização da tecnologia apropriada ao contexto do Sul Global; e de outro, o objetivo de que essa tecnologia não apenas seja mais adequada, mas que ela transforme efetivamente as relações de produção (inclusive no contexto local de aplicação), conduzindo conforme preconiza a economia solidária - a uma sociedade menos desigual e hierárquica. Nessa junção, Dagnino aponta as insuficiências da noção de tecnologia apropriada: embora problematize a insustentabilidade socioambiental e a subalternização provocadas pela tecnologia convencional, a tecnologia apropriada não inclui em seu escopo um projeto de transformação social mais radical - nem no âmbito cognitivo (falta-lhe uma visão mais crítica sobre a suposta neutralidade da tecnologia), nem no socioeconômico (não permite vislumbrar um caminho para a transformação das relações de produção). Ainda assim, ela supre uma lacuna do pensamento sobre a economia solidária, que em geral não tematizara de forma específica o papel da tecnociência.

Os trabalhos de Dagnino (2014, p. 23-24, 211-212) indicam os seguintes aspectos como características principais da tecnologia social:

1. "adaptada ao reduzido tamanho físico e financeiro";

2. "não discriminatória" e "liberada da diferenciação [...] entre patrão e empregado";

3. "orientada para um mercado interno de massa";

4. "libertadora do potencial e da criatividade do produtor direto", "é desenvolvida com a participação ativa, desde a sua concepção, de quem a necessita e vai usá-la”;

5. "orientada para a geração de trabalho e renda mediante a produção";

6. "seu foco são os segmentos sociais e econômicos referidos pela expressão 'economia informal' e que são 'candidatos' a integrar a Economia Solidária”;

7. “é reaplicável de modo autônomo"; 
8. “incorpora as dimensões de sustentabilidade econômica, social, cultural e ambiental e o crescente empuxo de participação social, com criatividade, originalidade, autonomia e soberania";

9. “demandará a compreensão da Tecnociência como uma construção social e política e a rejeição do mito da Neutralidade e do Determinismo". ${ }^{3}$

Como já é possível vislumbrar nessa lista de características, o autor define a tecnologia social em contraste à "tecnologia convencional", a mais valorizada no sistema capitalista; ele argumenta que esta é bastante adequada para maximizar o lucro de grandes empresas, mas não para promover inclusão social. Tipicamente, a tecnologia convencional busca aumentar a produtividade poupando mão de obra (deixando em segundo plano outras variáveis que também a afetam), o que leva ao desemprego e à ampliação da desigualdade socioeconômica; apresenta escalas ótimas de produção crescentes (ou seja, cada avanço tecnológico tende a exigir uma escala de produção e, consequentemente, um investimento de capital maior); é intensiva em insumos sintéticos (o que leva à degradação ambiental e à dependência de grandes fornecedores); e orientada prioritariamente aos mercados mais lucrativos, e não às necessidades das comunidades locais. Como veremos adiante, esse contraponto entre tecnologia social e convencional também é relevante no caso da produção de Cannabis para fins medicinais.

Embora o campo da economia solidária já debatesse os desafios e contradições da utilização de tecnologia convencional em seus empreendimentos, Dagnino (2014, p. 23, 13) é um autor que joga luz diretamente sobre essa dificuldade; para ele, a tecnologia social teria potencial de superar tais contradições, sendo "capaz de viabilizar economicamente os empreendimentos autogestionários", e devendo "ser considerada como uma plataforma cognitiva de lançamento da proposta da Economia Solidária”.

\section{Autocultivo e tecnologia social}

Nesta seção discutiremos a relação entre a noção de tecnologia social apresentada até aqui e o autocultivo de Cannabis. Para tanto, examinaremos agora alguns dados obtidos em pesquisa de campo; mais especificamente, em um total de sete entrevistas, ${ }^{4}$ realizadas com: o organizador de uma rede clandestina que doava o óleo extraído da Cannabis cultivada para pacientes que a utilizavam para fins medicinais (José Martins); duas pessoas que se preparavam para migrar para o autocultivo (Cidinha Carvalho e Margarete Brito); 5 duas pessoas que utilizavam o CBD produzido industrialmente (Katiele Fischer e Penny Howard); e dois advogados que davam assistência a cultivadores (Fernando Silva e Emílio Figueiredo).

Os primeiros dados que destacaremos indicam que a tecnologia utilizada para cultivo e extração do óleo era adequada para produção em pequena escala, com requisitos modestos de investimento de capital ao contrário do que tende a ocorrer na produção industrial, e tal como esperado em tecnologia social (em linha com a característica 1 da tecnologia social).

Em 2016, a rede clandestina funcionava atendendo 11 pacientes; Cidinha e Margarete, as familiares que migravam para o autocultivo, buscavam produzir a planta exclusivamente para tratar a epilepsia refratária de suas filhas.

Em entrevista, um dos organizadores da rede clandestina conta que foi feito um curso com

3 Embora elas apareçam em dois textos distintos de Dagnino (2014), agrupamos e numeramos essas características para simplificar a alusão a elas no restante do artigo, no qual são referidas como “característica 1, característica 2 etc. da tecnologia social”. As características 1-3 são oriundas das páginas 23 e 24; as características 5-9 são apresentadas entre as páginas 211 e 212 do livro de Dagnino; e a característica 4 combina elementos dos dois trechos.

4 Entrevistas realizadas originalmente para pesquisa de doutorado (Oliveira, 2016), onde são analisadas mais extensamente. Elas foram realizadas com participantes de grandes centros urbanos no Brasil (São Paulo e Rio de Janeiro) e uma participante dos Estados Unidos. São homens e mulheres acima de 30 anos.

$5 \mathrm{Na}$ época, as entrevistadas recebiam óleo da rede clandestina, mas estavam migrando para o autocultivo. Posteriormente à entrevista, conseguiram na Justiça o direito ao cultivo (Karam, 2018). 
um médico anônimo que conhecia a produção na Califórnia (EUA), fato que é corroborado por advogado que conhece os cultivadores (Fernando Silva, entrevistado em 2016). Foram comprados equipamentos adequados e importados cultivares da planta ricos em CBD.

Nossa turma já era cultivadora. A gente usava para relaxar, para estar junto. Vendo o caso das mães na imprensa e o custo, tivemos essa ideia. Na época, a gente via que um tubinho de canabidiol custava 500 dólares, 600 dólares. $\varepsilon$ a gente começou a pensar que a planta era grande, de graça. Era injusto. Esses pais estavam comprando suco de brócolis a preço de ouro. Pensamos: vamos selecionar aí umas plantas, pegar uma aí rica em CBD, todo mundo já tem experiência em cultivo... e foi assim. Assumimos o compromisso de dar para as pessoas que precisavam. A gente sabia que dar o óleo para uma tia moribunda com câncer era diferente de dar para crianças. Começamos a pesquisar. Procuramos médicos e passamos a nos inserir nas melhores práticas. (José Martins)

São pessoas estudadas, que têm muito fundamento, inclusive jurídico. Mas eles fazem na clandestinidade porque sabem que o entendimento atual é de que a atividade deles pode ser considerada como tráfico. Eles fazem com muito cuidado, mas com muito embasamento também. Inclusive eu imagino que eles estão muito preparados para o caso de algum dia algum deles tiver algum problema judicial, com muita documentação, muita prova pra mostrar que a proposta deles é lutar pela saúde das pessoas que precisam. (Fernando Silva)

O custo da produção era baixo e abria a possibilidade para o autocultivo por pessoas de renda média:

O custo, a contar de um cultivo já previamente existente, começa em $R S$ 5: o preço do vidro para alocar o óleo. Também tem o custo do envio, que vai depender da região do Brasil. É utilizado também óleo de abacate extravirgem para diluir o extrato de Cannabis. $O$ custo do óleo de abacate é de R\$ 20 o litro. A conta de luz, do cultivo inteiro, fica em torno de RS 2oo. (José Martins)
A rede clandestina, informa Martins, inicialmente distribuía o óleo por correio, de forma gratuita; mas dada a possibilidade de a rede sofrer acusação de tráfico de substâncias proibidas ou de falsificação de medicamentos, o caminho que buscavam era fomentar o autocultivo por terceiros. A opção pelo fomento ao autocultivo descentralizado também se devia ao aumento da procura pelo óleo oferecido por eles, o que passava a sobrecarregar a rede na sua capacidade de produção e nos seus custos.

Nossa ideia era muito legal, muito bacana, mas também não era sustentável. Nós temos uma limitação do plantio e também uma limitação financeira. Porque são pessoas que têm um tratamento contínuo e até hoje, depois de mais de dois anos, a gente fornece sem parar. Claro que não podemos chegar agora e dizer pra uma pessoa que se tornou dependente desse remédio: "vai lá e planta". Vamos ter que continuar doando para alguns. Nós tivemos uma opção social de pessoas de baixa renda, que não teriam acesso ao importado. Muitos não têm sequer a possibilidade de plantar. Eu tenho uma mãe que mora em Vigário Geral, praticamente num barraco. Ela não tem a menor condição de cultivar. Tinha uns encontros aqui no Instituto Estadual [Fernandes Figueira, ligado à Fiocruz] de pessoas que procuravam a importação e ela não ia. Ela dizia: "poxa, eu tenho vergonha, porque, se liberarem, eu não tenho [recursos para comprar]. Eu [só] tenho essa aposentadoria para me alimentar". É uma avó, na verdade, uma avó, com uma neta. $\varepsilon$ ela dizia: "eu tenho que me alimentar, comprar remédios, vestir, morar, pagar luz e telefone". E tudo isso é praticamente o preço de uma ampola dessas [de CBD]. (José Martins)

É interessante notar que, embora a rede tenha encontrado um limite da sua capacidade de produção, isso se deveu ao fato de ela distribuí-la de forma não-comercial, arcando com seus custos de maneira praticamente filantrópica (o que, embora destoe das características 3 e 5 da tecnologia social, está diretamente em linha com a característica 2). Além disso, era factível a replicação descentralizada da tecnologia, novamente com requisitos modestos de 
investimento de capital e produção viável em pequena escala (em linha com as características 7 e 1).

Cidinha Carvalho foi uma das pessoas que inicialmente teve acesso ao óleo distribuído pela rede, mas depois foi orientada a buscar a migração para o autocultivo. Ela chegou a fazer um curso em uma organização não-governamental (ONG) chamada Mamá Cultiva, no Chile, que ajudava familiares daquele país em situação similar (Mães..., 2016); após essa experiência, Cidinha entrou com uma ação judicial, em outubro de 2016, e eventualmente conseguiu liminar autorizando o autocultivo (Karam, 2018).

O contato com o autocultivo e a possibilidade de experimentar outro tipo de óleo que não o importado fez com que muitas famílias passassem a questionar a ideia de que só o CBD industrializado, "isolado", poderia ter efeito benéfico. Segundo Cidinha, sua filha conseguiu ter mais controle com o óleo produzido artesanalmente. Do mesmo modo, outras famílias passaram a fazer experimentos, muitas em parceria com seus médicos - como é o caso da entrevistada Margarete Brito, que também veio a obter liminar para o autocultivo (Karam, 2018).

Eu liguei para o meu médico, o Eduardo Faveret, $e$ falei sobre o que tinha descoberto sobre a maconha e ele falou: "eu sei, talvez eu fizesse a mesma coisa". Em outras palavras, ele falou algo como: "vamos aprender juntos, vamos mandar isso pra teste, enfim". Ele foi parceiro no primeiro momento para ouvir e aprender junto. Mas, assim, muito parceiro. (Margarete Brito)

As experiências dessas mães levaram à criação de duas associações de pacientes: a Associação de Apoio à Pesquisa e Pacientes de Maconha Medicinal (Apepi) e a Cultive Associação, comandadas respectivamente por Margarete Brito e Cidinha Carvalho, e que prestam assistência para o autocultivo. ${ }^{6} \mathrm{Na}$ Apepi, os associados pagam de $\mathrm{R} \$ 29,90$ a $\mathrm{R} \$ \mathbf{9 9 , 9 0}$ para ter acesso a informações e descontos em produtos. Da mesma forma, a Associação Brasileira de Pacientes de Cannabis Medicinal (AMA+ME), situada em Minas Gerais, também orienta seus associados sobre o autocultivo, e chegou a protocolar, com o Partido Popular Socialista (PPS), uma Ação Direta de Inconstitucionalidade (ADI/5708) em que defende que a proibição do autocultivo medicinal de maconha seria inconstitucional.

Como não é possível criar empreendimentos financeiros com o cultivo de Cannabis medicinal, que é ilegal no Brasil (Brasil, 2006, p. 11), ${ }^{7}$ as associações acabam por ser os espaços capazes de promover o uso autogestionado das tecnologias de produção independente de Cannabis para fins medicinais (tanto o cultivo como a extração do óleo) - algo que a rede clandestina, por seu status, não conseguiu alcançar. Além de orientarem as famílias em relação ao autocultivo, essas organizações buscam estabelecer a jurisprudência para que tais práticas possam ocorrer, a exemplo da ADI protocolada por uma das associações de pacientes.

Por meio da circulação do conhecimento sobre as tecnologias de produção e sobre as pesquisas na área, essas associações também são capazes de levar os pacientes a abordarem de forma crítica o composto importado e eventuais idealizações a respeito de sua tecnologia (em linha com a característica 9 da tecnologia social). 0 entrevistado Leandro Ramires, que está à frente da $\mathrm{AMA}+\mathrm{ME}$, é um dos que apresenta esse tipo de questionamento; para ele, foi atribuído um status de medicamento a um composto que, na prática, não é muito diferente do óleo extraído por meio do autocultivo:

O canabidiol é um azeite extra virgem. $\varepsilon$ isso, nada demais. É um suplemento alimentar que precisa de uma recomendação, não uma receita. $E$ aí, cria essa situação de remédio. Tem gente nos EUA que compra 1 kg de CBD por 10 mil dólares e cola um rótulo. A Hemp Meds vende um balde. Sujeito compra, bota num potinho, cola um rótulo e manda para o Brasil. o nivel é esse. (Leandro Ramires)

6 As atribuições podem ser verificadas em: <https://bit.ly/2MUgWqu> e <http://apepi.org/>. Acesso em: 3 maio 2019.

7 Essa situação destoa circunstancialmente das características 3 e 5 da tecnologia social; vale notar, porém, que caso não houvesse a proibição, a tecnologia poderia estar em linha com essas características. Além disso, há um alinhamento parcial com a característica 6 , se considerarmos que o caráter clandestino da rede é análogo à informalidade econômica. 
Ramires aponta para uma contradição muito citada por ativistas: o motivo pelo qual o CBD foi considerado substância controlada no Brasil, sendo que o principal fornecedor do composto importado a regulava como um suplemento alimentar (Oliveira, 2016). A contradição ganha um elemento adicional quando se debate o preço do composto; que, considerando variações cambiais e custo da importação, poderia chegar a R\$ 10 mil mensal no período, dispêndios que passaram a recair sobre o Governo Federal e o SUS após ações judiciais de pacientes (Juiz..., 2016). Oliveira (2016) aponta alguns fatores que podem ajudar a explicar a aparente incompatibilidade da decisão da Anvisa: pressões políticas para não aproximar a discussão dos debates de descriminalização ou legalização da maconha, além de uma pressão conjunta e, por vezes, antagônica de famílias e pesquisadores: as primeiras pressionavam pela importação do composto imediatamente, enquanto os segundos ponderavam os riscos de uma regulamentação indiscriminada.

Mesmo dentre aqueles que usam o composto importado, a ausência de protocolos para a administração do composto e a pouca informação disponível antes da reclassificação do CBD pela Anvisa acabou por fomentar a experimentação autônoma, em busca de práticas que oferecessem respostas benéficas aos sintomas. Katiele Bortoli Fischer (entrevistada em $1^{\circ}$ de abril de 2016), mãe de portadora de epilepsia refratária e utilizadora do CBD importado, acompanhava a evolução da filha com tabelas e gráficos diários, em que contabilizava a quantidade de convulsões (Oliveira, 2016). Também a entrevistada Penny Howard, que tratou filha com epilepsia, afirma que foi necessário aprender que o CBD era diferente dos medicamentos anticonvulsivantes tradicionais, e que com ele não precisava temer a overdose, por exemplo: o CBD aumentava a possibilidade de que pacientes e familiares estivessem no comando do tratamento.

$\varepsilon$ como estávamos dando remédios com riscos de superdosagem, acho que tínhamos medo de ficar com o suplemento nutricional e assumirmos o comando. E o lance do produto é que não havia superdosagem. A única coisa que ele pode fazeré te deixar cansado. $\varepsilon$ quando as pessoas entendiam isso, elas ficam felizes com os resultados e se sentiam confortáveis. Pais podiam assumir o comando e alguns deles descobriam que não funcionava, mas isso não os desencorajava. Eles sempre podiam tentar outra coisa, outro produtor, ou um produto com mais THC. (Penny Howard)

Se é verdade, por um lado, que tanto no autocultivo como na utilização do composto importado há espaço para o engajamento ativo dos usuários e para o uso de tecnologias próprias - por exemplo, avaliando e adaptando os protocolos de administração de maneira a maximizar os efeitos terapêuticos -, é preciso considerar também que o autocultivo oferece maior possibilidade de escolha sobre as características do produto e sua composição final - por exemplo, com a variação da composição final obtida por meio da escolha de cultivares específicos, como relatado por entrevistados da rede clandestina. Nesse sentido, o autocultivo, para além de propiciar uma indiferenciação entre patrão e empregado (em linha com a característica 2), em função do caráter razoavelmente horizontal das relações na rede e associações, propicia também uma indiferenciação entre produtor e consumidor. Nesse sentido, Cidinha Carvalho descreve como, em sua experiência no Chile, as mães passavam a ter a possibilidade de ir fabricando e testando o produto em busca daquela combinação de cultivares e composições que dessem a melhor resposta de tratamento em seus casos específicos (diretamente em linha com a característica 4).

Eu cheguei a ir ao Chile, participei da oficina das mães, da Mamá Cultiva, da fundação Daya, aprendi a fazer o óleo ali no Chile e eu conversei com muitas mães lá e percebi que... porque assim, a minha filha... o óleo que eles fazem é das flores, realmente das flores, que é onde contém todos os canabinoides, né? O que gera aquele efeito. $\varepsilon$ as mães lá do Chile, elas têm a possibilidade de ir testando até encontrar uma que dê a melhor resposta no tratamento. $\varepsilon$ muitas mães que conversei, a melhor resposta encontrada... é 1 por $1 \mathrm{em}$ THC. Mais THC do que CBD. $E$ aqui o 
THC é banalizado. É visto como parte do mal, e não é nada disso. A minha filha está progredindo com o THC. Não tem que ouvir só o Crippa que está sintetizando a planta. Tem que ouvir todos os lados, abrir as possibilidades. Se acha que o artesanal é perigoso, que é tabu, então, que teste, que dê a oportunidade de fazer pesquisas. Por que não faz isso? É mais fácil falar sem ver os resultados. $E$ aí? Tem muitas crianças que não tem resposta positiva com o importado. Então, eu não vou importar só pra ficar na legalidade. Eu preciso da minha filha viva. (Cidinha Carvalho)

A experiência de Cidinha e de outros cultivadores, bem como a atuação das associações que divulgam a prática, permite a abertura de outras possibilidades para a produção de compostos com fins medicinais (em linha com a característica 8 no que diz respeito a "autonomia e soberania", particularmente se considerarmos que o autocultivo se coloca como alternativa à aquisição de produto industrial importado). Essa ideia surge no depoimento do advogado Emílio Figueiredo, que atende pessoas interessadas no autocultivo:

Ninguém quer ficar importando, se sujeitando, $e$ ninguém quer depender do Estado para o remédio. Todo mundo que já compreendeu que a Cannabis medicinal pode ser em feita em casa, no quintal de casa, eles querem a autorização para fazer o remédio dos seus filhos ou deles próprios. (Emílio Figueiredo)

Sistematizamos os achados de campo descritos anteriormente no Quadro 1, indicando a presença (ou ausência, ou presença parcial), nas práticas de autocultivo de maconha medicinal abordadas aqui, das características que Dagnino (2014) propõe para a tecnologia social:

\section{Quadro I - As características da tecnologia social no autocultivo de Cannabis}

\begin{tabular}{|c|c|}
\hline Características da tecnologia social & Presença no autocultivo de Cannabis \\
\hline (1) "adaptada ao reduzido tamanho". & $\begin{array}{l}\text { Sim: famílias e redes fabricam em pequena escala, para consumo } \\
\text { próprio ou doação. }\end{array}$ \\
\hline $\begin{array}{l}\text { (2) "não discriminatória"; indistinção } \\
\text { "patrão e empregado". }\end{array}$ & $\begin{array}{l}\text { Sim: produção e distribuição não-comercial; } \\
\text { horizontalidade na rede e associações. }\end{array}$ \\
\hline $\begin{array}{l}\text { (3) "orientada para um } \\
\text { mercado interno de massa". }\end{array}$ & $\begin{array}{l}\text { Parcial: produção orientada a necessidades internas (mas de público } \\
\text { restrito, e organizada de forma não-comercial). }\end{array}$ \\
\hline $\begin{array}{l}\text { (4) "libertadora do potencial e da criatividade } \\
\text { do produtor direto", "desenvolvida com a } \\
\text { participação ativa [...] de quem a necessita". }\end{array}$ & $\begin{array}{l}\text { Sim: consumidores finais (eventualmente os próprios produtores) } \\
\text { envolvidos e engajados no aprimoramento e adequação da tecnologia. }\end{array}$ \\
\hline $\begin{array}{l}\text { (5) "orientada para a geração de trabalho e renda } \\
\text { mediante a produção". }\end{array}$ & Não: produção organizada de forma não-comercial. \\
\hline $\begin{array}{l}\text { (6) "seu foco são os segmentos [da] 'economia } \\
\text { informal' e que são 'candidatos' a integrar a } \\
\text { Economia Solidária". }\end{array}$ & $\begin{array}{l}\text { Parcial: caráter clandestino análogo à economia informal; afinidade } \\
\text { geral com características da economia solidária (autogestão, } \\
\text { propriedade coletiva). }\end{array}$ \\
\hline (7) "é reaplicável de modo autônomo". & Sim: rede e associações fomentam replicação. \\
\hline $\begin{array}{l}\text { (8) "sustentabilidade econômica, social, } \\
\text { cultural e ambiental [...] e participação social, } \\
\text { [...] autonomia e soberania". }\end{array}$ & $\begin{array}{l}\text { Parcial: valorização de autonomia e soberania (substituição } \\
\text { de importado industrial); elementos insuficientes para avaliar } \\
\text { sustentabilidade ambiental, cultural etc. }\end{array}$ \\
\hline $\begin{array}{l}\text { (9) "demandará a compreensão da Tecnociência } \\
\text { como uma construção social e política e a rejeição } \\
\text { do mito da Neutralidade e do Determinismo". }\end{array}$ & $\begin{array}{l}\text { Parcial: questionamento (pouco desenvolvido) da idealização } \\
\text { de tecnologia de ponta industrial, de seu caráter neutro e de sua } \\
\text { adequação ao contexto brasileiro. }\end{array}$ \\
\hline
\end{tabular}


Tecnologia social, novas epistemologias e ciência cidadã

Antes de prosseguir para as conclusões, faremos nesta seção breves considerações sobre a relação entre a noção de tecnologia social e as chamadas epistemologias do Sul.

O modelo de tecnologia social proposto por Dagnino (2014) encontra pontos de contato com os estudos sobre novas epistemologias do Sul, que propõem conferir legitimidade a saberes historicamente não reconhecidos e ligados a práticas de resistência e lutas contra a opressão (Santos, 2019). Como visto, para que uma prática seja considerada tecnologia social, dentre outros critérios, ela deve integrar "participação social, com criatividade, originalidade, autonomia e soberania" (Dagnino, 2014, p. 212). Contudo, embora uma prática com autonomia de seus participantes potencialmente abra mais espaço para que saberes e modos de vida sejam visibilizados e considerados, é um desafio integrar esses saberes ao modo de produção capitalista global sem que sejam descaracterizados.

Entre os elementos desse desafio, Boaventura Santos (2019) aponta as questões sobre autoria: os sujeitos do conhecimento de muitos saberes são coletivos e não personalizados, ao passo que, na produção capitalista, a autoria é pensada de viés individualizado e atrelado ao instrumento da propriedade intelectual, que permite a transformação de tais saberes em mercadorias, majoritariamente detidas por grandes corporações. Essa é uma das razões pelas quais não será possível haver justiça social sem justiça cognitiva, como argumenta Santos.

Outro aspecto desse desafio consiste na necessidade de repensar o modelo universalista da ciência, que considera haver categorias únicas para validação da legitimidade de um saber, e acaba por validar apenas o conhecimento produzido estritamente no interior do campo científico. 0 caso analisado aqui aponta para o potencial da incorporação de atores externos a esse campo no processo de construção do conhecimento; as discussões sobre ciência cidadã ou aberta vão em sentido similar, sugerindo que essa incorporação, feita de maneira criteriosa, pode favorecer não só a qualidade e eficácia desse processo, como também a democratização da agenda científica, aproximando-a de interesses sociais amplos (e não apenas os de grandes corporações). É clara também, ademais, a necessidade de reavaliar alguns dos pressupostos desse modelo universalista, como a separação entre ética e política, entre ciência e valores, entre natureza e cultura (Lacey, 2009; Latour, 1994; Santos, 2019).

Por fim, as epistemologias do Sul nos provocam a considerar que as categoriais de conhecimento estão permeadas por pressupostos de inferioridade étnico-culturais e pela herança da colonização; e que há, assim, uma colonialidade nos próprios saberes, da mesma forma que há uma colonialidade das relações de produção. Ao mesmo tempo, as relações de produção no Sul Global foram diretamente atravessadas por uma outra categoria colonial: a raça, que historicamente distinguiu assalariados de não-assalariados (Quijano, 2005). Transformações na esfera produtiva, assim, dependem de transformações cognitivas, uma vez que práticas da economia liberal não compatíveis com a definição de tecnologia social possuem paralelismos com categorias construídas pela ciência moderna, com seu caráter "ahistórico", transcendente, universal e metafísico (Dávalos, 2011).

\section{Considerações finais}

Nossa análise sugere uma afinidade significativa entre as práticas abordadas de autocultivo de Cannabis para fins medicinais, e as características da tecnologia social tal como formuladas por Dagnino (2014). Acreditamos, portanto, que em seu contexto localizado, tais práticas tendem a favorecer a busca de desenvolvimento socioeconômico (materializado na melhoria das condições de vida dos pacientes que utilizam tais medicamentos, e na ampliação das capacidades produtivas dos atores envolvidos), aliado à transformação de relações sociais rumo a uma realidade menos desigual e hierarquizada. É evidente, nesse sentido, o contraste com a situação observada na aquisição do medicamento industrial importado, em que o acesso ao medicamento é profundamente desigual (só existe para quem pode pagar seus altos custos), e o Brasil se insere mundialmente de forma subordinada aos países do Norte Global (dos quais importa o CBD industrializado). Enfocar o autocultivo da Cannabis da perspectiva da tecnologia 
social também traz contribuições importantes para o debate do seu uso medicinal, permitindo lidar melhor com as questões da autonomia tecnológica e da sustentabilidade socioambiental - questões menos consideradas na perspectiva da tecnologia convencional, e que podem ser favorecidas com soluções de menor escala e produção local.

Duas ponderações, porém, são relevantes nesta análise: uma relativa a possíveis limitações da noção de tecnologia social; e outra relativa aos riscos envolvidos na adoção de uma tal estratégia na produção de medicamentos, e ao potencial de abordagens de ciência cidadã para mitigá-los.

A primeira ponderação é que, na análise deste caso, é possível perceber o que talvez seja uma limitação da noção de tecnologia social. As características da tecnologia social que não se manifestam nas práticas analisadas (3 e 5) são aquelas ligadas à produção para mercado (ainda que de forma solidária) e, consequentemente, à geração de renda; o distanciamento da tecnologia social ocorre, aqui, porque o autocultivo é realizado como produção não-comercial. Isso talvez não seja um acaso, pois Dagnino (2014) vê na transformação do setor produtivo um objetivo central da tecnologia social. Mas será que a produção não-comercial e voltada à satisfação direta de necessidades dos produtores (ou dos pacientes beneficiados por eles, no caso da rede) tem mesmo menor potencial de transformação social do que se fosse conduzida de forma comercial, como parece sugerir a perspectiva de Dagnino? No contexto deste caso, isso não parece evidente, e requereria uma comparação mais detalhada. Essa aparente limitação sugere a possibilidade de que a noção de tecnologia social não seja plenamente capaz de apreciar o potencial transformador de práticas que não tenham o desenvolvimento econômico como principal meta, mas sim o atendimento de necessidades diretas (por exemplo, de forma autônoma ou comunitária).

Entendemos que o estudo sobre o autocultivo aqui apresentado pode contribuir com critérios adicionais para a definição de tecnologia social proposta por Dagnino (2014), sanando em alguma medida essas limitações, mas sem ferir os princípios gerais do conceito: o de tecnologia apropriada ao Sul Global e à transformação das relações de produção. Nesse sentido, propomos que a característica 3, que descreve a tecnologia social como "orientada para um mercado interno de massa” (Dagnino, 2014, p. 23), poderia ser acrescentada da sentença "ou para mudanças de padrão de consumo coletivos”. Também a característica 5, que descreve a tecnologia social como "orientada para a geração de trabalho e renda mediante a produção" (Dagnino, 2014, p. 211), poderia receber o acréscimo "ou orientada para satisfação de necessidades diretas ou comunitárias”. Baseamos essas duas propostas no fato de que as análises marxistas às vezes subestimam a relevância no capitalismo das práticas relacionadas ao cuidado ou à reprodução da vida (como o trabalho doméstico, mas também a saúde) (Federici, 2017), possivelmente pelo fato de serem consideradas trabalho improdutivo da perspectiva do capital, na terminologia marxiana. Defendemos, em contraste, que práticas que se adaptam à economia de regiões do Sul Global e fortalecem mudanças coletivas podem contribuir para mudanças de relações de produção, mesmo quando não são voltadas à geração de renda, mas à satisfação de necessidades diretas (inclusive as relacionadas à saúde) que de outra forma seriam supridas por produção mercantil; isso é válido no âmbito individual (práticas de autocultivo individual, porém replicáveis), e ainda mais no comunitário (formação de redes de autocultivo não comerciais).

E na característica 2, que descreve a tecnologia social como não discriminatória, entendemos que seja importante incluir explicitamente como meta, no mínimo, a igualdade de gênero e étnico-racial. Isso implicaria pautar a integração ativa de mulheres, negros e minorias à produção, com divisão equitativa de cargos e tempo de trabalho; além de renda, quando houver. No ativismo e na defesa da prática do autocultivo de Cannabis, é notável a participação ativa de mulheres; por outro lado, os atores mais centrais dessa defesa pertenciam a uma classe média urbana branca (Oliveira, 2016), enquanto as vítimas majoritárias da guerra às drogas são a população negra e periférica. Entendemos que tanto a categoria de gênero como de raça contribuem para a reprodução de desigualdades quando estabelecem cortes entre um trabalho que será remunerado, mal (ou não) remunerado, e até tornado ilegal; reproduzindo assim ciclos de pobreza e criminalização em regiões menos favorecidas (Federici, 2017; Quijano, 2005). 
Para além dessas ponderações e propostas, porém, este trabalho chama atenção para a especificidade da área da saúde no que tange ao caráter produtivo da tecnologia social. Nessa área, entendemos que - exceto em situações específicas de lacuna de produção medicamentosa e de doenças em que compreende-se os riscos assumidos devido à gravidade da condição - a produção unicamente caseira, como feita pelo autocultivo, não seria um horizonte geral desejável para a área da saúde como um todo, tendo em vista riscos associados a possíveis variações da qualidade da produção. As práticas descritas se desenvolveram na ausência de uma legislação específica, e a própria regulamentação do CBD e a liberação do autocultivo se deram pela gravidade das condições, em que só se concebeu o uso via acesso expandido - como o feito para medicamentos que ainda estão em desenvolvimento clínico, em situações como a do uso compassivo:

Uso compassivo: disponibilização de medicamento novo promissor para uso pessoal de paciente não participante de programa de acesso expandido ou de pesquisa clínica, ainda sem registro na Anvisa, que esteja em processo de desenvolvimento clínico, destinado a pacientes portadores de doenças debilitantes graves e/ou que ameacem a vida, sem alternativa satisfatória com produto registrado no país. (CFM, 2014)

Tendo em vista essa ressalva, contudo, concebemos ser possível uma produção em que, analisados previamente os potenciais riscos de uma produção caseira da substância e do óleo rico em CBD, cidadãos poderiam ser orientados e apoiados por centros de pesquisa públicos renomados, a fim de limitar tais riscos por meio de oferta de capacitação e de serviços de teste e avaliação de resultados. Adentra-se aqui em um debate que envolve categorias como a de ciência cidadã, em que cientistas e cidadãos trabalham juntos tanto na coleta como na interpretação de dados (Halavais, 2013). Essa perspectiva entende a especificidade da trajetória de alguns cidadãos, como aqueles que, por serem portadores doenças crônicas, acabam tendo muito contato com a produção científica e conhecimento da sua própria condição.

Entendemos que essa última proposta é um grande desafio, dada, entre outros fatores, a prevalência do modelo biomédico e da medicina científica, que predominantemente se utilizam de formas purificadas e descontextualizadas da produção de evidências. Esses modelos dão pouco espaço para a produção autônoma ou em colaboração com o campo científico, e, por meio de suas instituições, aprofundam a separação entre medicina e saber leigo; no caso do CBD e do autocultivo, essa separação estrita não se mostrou adequada nem suficiente para as necessárias respostas contextuais. A controvérsia apresentada mostra essa disputa: um dos principais argumentos levantados contra o autocultivo é o desejo de que a produção siga parâmetros rígidos de padronização - parâmetros que, hoje, só podem ser atingidos na produção industrial. ${ }^{8}$ Nossa proposta almeja construir um espaço de conciliação entre esses saberes e práticas distintos, na medida em que propõe conceber as necessárias padronizações de forma a que não sejam possíveis em um único modo de produção (o industrial), mas também no autocultivo enquanto tecnologia social. A estrutura mais descentralizada da tecnologia social também permite a visibilidade de (e maior abertura a) outras epistemologias e "racionalidades leigas", que auxiliam na produção de respostas inovadoras e mais adequadas a diferentes contextos sociais e culturais (Alves, 2015). 0 assunto, no entanto, é extenso e merecerá abordagem mais aprofundada em trabalhos futuros.

\section{Referências}
ALVES, F. Racionalidades leigas e produção local de saberes em saúde. In: CARAPINHEIRO, G.; CORREIA, T. Novos temas da saúde, novas questões sociais. Lisboa: Mundos Sociais, 2015.

8 Essa observação tem por base os parâmetros da Anvisa para a aprovação de medicamentos, em que apenas uma empresa devidamente registrada pode solicitar o registro. Devem ser apresentados uma extensa documentação, em que conste todos os testes necessários, segundo informações da Anvisa (Registro..., 2018). O caso do CBD, contudo, foi atípico, e o processo de regulamentação foi feito a partir de pesquisas da área técnica da própria Anvisa e consultas a instituições de pesquisa, médicos e pacientes (Oliveira, 2016). 
p. 113-128. Disponível em: <https://bit.ly/2YpdqtM>. Acesso em: 11 jun. 2020.

ANVISA - AGÊNCIA NACIONAL DE VIGILÂNCIA SANITÁRIA. Diretoria Colegiada. ResoluçãoRDC ${ }^{0}{ }_{3}$, de 26 de janeiro de 2015. Diário Oficial da União, Brasília, DF, 28 jan. 2015a. Seção 1, p. 53. Disponível em: <https://bit.ly/3hmDcHx>. Acesso em: 13 jul. 2016.

ANVISA - AGÊNCIA NACIONAL DE VIGILÂNCIA SANITÁRIA. Diretoria Colegiada. ResoluçãoRDC n ${ }^{0}$ 17, de 6 de maio de 2015. Diário Oficial da União, Brasília, DF, 8 maio 2015b. Seção 1, p. 50-51. Disponível em: <https://bit.ly/2BYzqUI>. Acesso em: 10 mar. 2020.

BRASIL. Lei ${ }^{\circ}$ 11.343, de 23 de agosto de 2006. Diário Oficial da União, Brasília, DF, 14 ago. 2006. Seção 1 , p. 2. Disponível em: <https://bit.ly/37jREvu>.

Acesso em: 19 jul. 2016.

BRUCKI, S. M. D. et al. Cannabinoids in neurology Brazilian Academy of Neurology. Arquivos de NeuroPsiquiatria, São Paulo, v. 73, n. 4, p. 371-374, 2015.

CANNABIS medicinal no Brasil: veja o que muda com as novas regras da Anvisa. G1, [S.l.], 3 dez. 2019. Disponível em: <https://glo.bo/2MXiwrz>.

Acesso em: 10 mar. 2020.

CFM - CONSELHO FEDERAL DE MEDICINA. Resolução CFM n 2.113/2014. Diário Oficial da União, Brasília, DF, 16 dez. 2014. Seção 1, p. 183. Disponível em: <https://bit.ly/2YpiRc2>.

Acesso em: 13 jul. 2016.

COLLUCCI, C. “Califórnia brasileira”, Paraíba tem plantio de maconha para 2.50o pacientes. Folha de S.Paulo, São Paulo, 29 set. 2019a. Disponível em: <https://bit.ly/2C1ELdZ>. Acesso em: 11 mar. 2020.

COLLUCCI, C. Ações para acesso à Cannabis crescem $1.750 \%$ em quatro anos em São Paulo. Folha de S.Paulo, São Paulo, 5 out. 2019b. Disponível em: <https://bit.ly/2AZMOr5>. Acesso em: 11 mar. 2020.

CRUZ, C. Anvisa aprova proposta que simplifica importação de produtos à base de canabidiol. G1, [S.l.], 22 jan. 2020. Disponível em: <https://glo.bo/2zpxfIL>. Acesso em: 10 mar. 2020.
DADOS, N.; CONNELL, R. The Global South. Contexts, Thousand Oaks, v. 11, n. 1, p. 12-13, 2012. Disponível em: <https://bit.ly/3cWgEu3>. Acesso em: 6 maio 2020.

DAGNINO, Renato. Tecnologia Social: contribuições conceituais e metodológicas. Campina Grande: EDUEPB, 2014. (Tecnologia Social, 2). Disponível em: <http://books.scielo.org/id/7hbdt >. Acesso em: 1 maio 2019.

DÁVALOS, P. Comentario: El Sumak Kawsay (Buen Vivir) y la crítica a la teoría económica como ideología. Polémika, Quito, v. 3, n. 7, p. 17-31, 2011.

DUNN, P. D. Appropriate technology: technology with a human face. Londres: Macmillan Education UK, 1978.

ESCOBAR, A. Territories of difference: place, movements, life, redes. Durham: Duke University Press, 2008.

FANON, F. Os condenados da terra. Rio de Janeiro: Civilização Brasileira, 1968.

FEDERICI, S. Calibã e a bruxa: mulheres, corpo e acumulação primitiva. Tradução Coletivo Sycorax. São Paulo: Elefante, 2017.

GURGEL, H. L. C. et al. Uso terapêutico do canabidiol: a demanda judicial no estado de Pernambuco, Brasil. Saúde e Sociedade, São Paulo, v. 28, n. 3, p. 283-295, 2019.

HALAVAIS, A. Home made big data Challenges and opportunities for participatory social research. First Monday, Bridgman, v. 18, n. 10, 2013. Disponível em: <https://bit.ly/2XVIMsJ>.

Acesso em: 4 maio 2019.

HERRERA, A. Ciencia y política en América Latina. México: Siglo XXI, 1971.

JUIZ obriga União a pagar tratamento com canabidiol a paciente em Franca. G1, Ribeirão Preto, 16 mar. 2016. Disponível em: 〈https://glo.bo/3cW7gXc〉. Acesso em: 10 mar. 2020.

JUSTIÇA autoriza família a cultivar maconha em casa para tratar filha. Bom Dia Brasil, [S.l.], 24 nov. 2016. Disponível em: <https://glo.bo/3hjIEuV>. Acesso em: 3 maio 2019. 
KARAM, L. Mães que lutam pela legalização contam como maconha melhorou a saúde dos filhos. Marie Claire, 9 jan. 2018. Disponível em: <https://glo.bo/2XUKFG7>. Acesso em: 3 maio 2019.

LACEY, H. O lugar da ciência no mundo dos valores e da experiência humana. Scientiae Studia, São Paulo, v. 7, n. 4, p. 681-701, 2009.

LATOUR, B. Jamais fomos modernos: ensaio de antropologia simétrica. Rio de Janeiro: Ed. 34, 1994.

MÃES plantam maconha para produzir remédios para os filhos no Chile. Fantástico, [S.l.], 8 maio 2016. Disponível em: <https://glo.bo/2YrXgzM>. Acesso em: 13 jul. 2016.

OLIVEIRA, L. L.; RIBEIRO, L. R. Discursos médicos e jurídicos sobre maconha na Paraíba: a judicialização do direito ao acesso à maconha medicinal. Revista de Estudos Empíricos em Direito, São Paulo, v. 4, n. 2, p. 55-74, 2017. Disponível em: <https://bit.ly/3cXpQhu>. Acesso em: 11 mar. 2020.

OLIVEIRA, M. B. O medicamento proibido: como um derivado da maconha foi regulamentado no Brasil. 2016. 313 f. Dissertação (Mestrado em Divulgação Científica e Cultural) - Laboratório de Estudos Avançados em Jornalismo, Instituto de
Estudos da Linguagem, Universidade Estadual de Campinas, Campinas, 2016.

PAIS lutam na Justiça por liberação de remédio derivado da maconha. Fantástico, [S.l.], 30 mar. 2014. Disponível em: <https://glo.bo/3dU3uis>. Acesso em: 24 jul. 2016.

QUIJANO, A. Colonialidade do poder, eurocentrismo e América Latina. In: LANDER, E. (Org.). $A$ colonialidade do saber: eurocentrismo e ciências sociais. Perspectivas latino-americanas. Buenos Aires: Clacso, 2005. p. 117-142. Disponível em: <https://bit.ly/3dWLdkw>. Acesso em: 12 jun. 2020.

REGISTRO de novos medicamentos: saiba o que é preciso. Anvisa, Brasília, DF, 26 nov. 2018. Disponível em: <https://bit.ly/2B2iyfc .

Acesso em: 19 mar. 2020

SANTOS, B. S. O fim do império cognitivo: a afirmação das epistemologias do sul. Belo Horizonte: Autêntica, 2019.

SCHUMACHER, E. F. Small is beautiful: a study of economics as if people mattered. Londres: Blond and Briggs, 1973.

SINGER, P. Introdução à economia solidária. São Paulo: Fundação Perseu Abramo, 2002.

\section{Agradecimentos}

Agradecemos aos/às pareceristas anônimos/as do periódico, pela leitura atenta, pelo diálogo e pelas contribuições que ofereceram ao artigo.

\section{Contribuição dos autores}

Oliveira contribuiu na coleta de dados, análise e elaboração do texto. Akerman e Vieira contribuíram na análise e na elaboração do texto.

Recebido: 23/03/2020

Reapresentado: 10/05/2020

Aprovado: 29/05/2020 